\title{
DOUBLE BIND E ESCRITA: a poética da tradução em textos da literatura do Quebec
}

\author{
Renato Venancio Henriques de Sousa \\ Doutor \\ Universidade do Estado do Rio \\ de Janeiro \\ E-mail: \\ rvhsousa@uol.com.br
}

Resumo: Nosso trabalho pretende refletir sobre a noção de double bind (DERRIDA, 2002) a partir de textos da literatura do Quebec que ora tematizam ora problematizam a questão da tradução. Trata-se de uma produção marcada pelo que Sherry Simon denomina como um "processo 'inacabado' de tradução” (SIMON, 1994), na qual se faz referência a uma diversidade de códigos linguísticos e culturais. Nossa leitura vai privilegiar textos do escritor de origem brasileira Sergio Kokis (1996) e da autora e roteirista Monique Proulx (2005).

Palavras-chave: Tradução. Double bind. Literatura canadense de língua francesa. Escrita migrante. Identidade.

Abstract: Il nostro studio pretende di riflettere sulla nozione di double bind (DERRIDA, 2002), partendo da testi letteratri di Quebec che ora tematizzano ora problematizzano la questione della traduzione. Si tratta di una produzione segnata da quello che Sherry Simon chiama un "processo 'incompiuto' di traduzione" (SIMON, 1994), nella quale si fa riferimento a una diversità di codici linguistici e culturali. La nostra lettura priviligerà testi dello scrittore di origine brasiliana Sergio Kokis (1996) e dell'autore e sceneggiatore Monique Proulx (2005).

Key words: Traduzione. Double bind. Letteratura canadese in lingua francese. Scrittura migrante. Identità. 
DOUBLE BIND E ESCRITA: a poética da tradução em textos da literatura do Quebec.

Renato Venancio Henriques de Sousa

\section{Introdução}

A pesquisadora canadense Sherry Simon aborda em Le trafic des langues: traduction et culture dans la littérature québécoise, entre outras coisas, a questão da tradução como tema privilegiado da literatura quebequense contemporânea. Ao trabalhar o imaginário dos autores de ambas as línguas oficiais do país, fecundando-lhes as obras de modo recorrente, a tradução aparece como um leitmotif, particularmente entre os autores da chamada escrita migrante. Daí poder-se falar numa "poética da tradução", definida pela autora nos seguintes termos:

\footnotetext{
Trata-se de um procedimento de criação interlinguístico que resulta na manifestação de "efeitos de tradução" no texto, de elementos de interferência que criam uma certa abertura ou "fraqueza" no plano do domínio linguístico e do tecido de referências às quais o texto se liga.[...] A poética da tradução utiliza, pois, a relação com a língua estrangeira para alimentar a criação, desenvolvendo-se neste espaço fronteiriço no qual criação e transferência, originalidade e imitação, autoridade e submissão se confundem (SIMON, 1994, p. 19-20). ${ }^{1}$
}

Atuando como um dos diversos mecanismos do repertório das figuras pós-modernas da repetição, mecanismos que põem em movimento uma série de procedimentos de reciclagem de produtos culturais de "segunda mão" nos quais se coloca a problemática e, no limite, impossível relação com a origem (e a originalidade), a tradução convoca um conjunto de saberes e técnicas que produzem novas leituras a partir de fontes conhecidas, sendo, como diz Simon, ao mesmo tempo, "repetição e novidade" (SIMON, 1994, p. 75-76, grifo da autora). Neste contexto, os autores marcados por situações de

${ }^{1}$ Atente-se para a irrupção, nos anos 70, no Quebec, de uma prática tradutória que, no contexto de afirmação nacional da identidade quebequense, busca inscrever a "québécité" no texto de origem estrangeira. A chamada "tradução identitária", que floresceu no meio teatral, foi objeto de um notável estudo de Annie Brisset intitulado Sociocritique de la Traduction: théâtre et altérité au Québec (1968-1988). (BRISSET, 1990. Cf. capítulo IV, p. 259-309). V. ainda SIMON, 1994, p. 22. 
DOUBLE BIND E ESCRITA: a poética da tradução em textos da literatura do Quebec.

Renato Venancio Henriques de Sousa

liminaridade linguística e/ou cultural, seriam, em princípio, mais sensíveis a uma tal poética tradutória.

Simon busca demonstrar como a "recusa" da tradução, no interior das literaturas nacionais, baseia-se numa noção fechada de cultura. A partir do momento em que esta última é vista como "um jogo de diferenças", pode-se "conceber a passagem linguística e cultural como um elemento essencial de criação coletiva, portanto, da identidade cultural” (SIMON, 1994, p. 47). A ensaísta se interessa, pois, em compreender e analisar os desafios colocados pelo que ela chama de "literatura das fronteiras". Segundo ela,

é na literatura que surge nas fronteiras das identidades nacionais que a "contribuição" da tradução se manifesta de modo particularmente transparente. As narrativas da imigração e do exílio, as obras que relatam as experiências de deslocamento e de relocalização próprias ao contexto pós-colonial estão repletas do imaginário de diversas línguas. [...] Com efeito, os questionamentos identitários dos escritores "transfronteiriços" expressam as preocupações comuns a todo projeto de escrita, acentuadas pela aceleração dos fenômenos de cruzamentos no mundo contemporâneo (SIMON, 1994, p. 25).

Escrevendo sobre o processo "inacabado" de tradução presente em diversos textos híbridos, Simon diz o seguinte:

Como dar conta destas realidades plurais? Como classificar um texto cujas marcas linguístico-culturais são incertas? Pode-se traduzir um texto tornando visível seu pertencimento a vários códigos linguísticos? Quando o texto faz referência a uma multiplicidade de códigos, falaremos de um processo "inacabado" de tradução. Esta não logra a totalidade de seu trajeto naturalizante, criando, antes, um espaço que demonstra a interdependência do aqui e do alhures (SIMON, 1994, p. 28-29, grifo nosso). ${ }^{2}$

\footnotetext{
${ }^{2}$ Na página 181, Simon escreve o seguinte: "Estamos habituados a conceber a tradução como uma operação de transmissão de um texto, escrito em uma língua, pertencendo a uma cultura, para uma nova residência linguístico-cultural. O que acontece quando as próprias línguas e as culturas 'de partida’ já revelam-se plurais? Então é necessário reconceptualizar a tradução para poder considerála uma operação que não chega sempre a um resultado homogêneo, mas que - a exemplo das identidades culturais do mundo contemporâneo - confronta-se permanentemente com $\mathrm{O}$ inacabado" (SIMON, 1994, p. 181, grifo da autora).
} 
DOUBLE BIND E ESCRITA: a poética da tradução em textos da literatura do Quebec.

Renato Venancio Henriques de Sousa

A estudiosa aproxima-se aqui da reflexão de Jacques Derrida, que numa passagem de Torres de Babel aponta os limites das teorias da tradução no que diz respeito à economia do texto plurilíngue. Para Derrida, tais teorias "tratam bem frequentemente das passagens de uma língua a outra e não consideram suficientemente a possibilidade para as línguas, a mais de duas, de estarem implicadas em um texto" (DERRIDA, 2002, p. 20, grifo do autor). Tal como Simon, Derrida faz três perguntas, a saber: "Como traduzir um texto escrito em diversas línguas ao mesmo tempo? Como 'devolver' o efeito de pluralidade? E se se traduz para diversas línguas ao mesmo tempo, chamar-seá a isso traduzir?" (DERRIDA, 2002, p. 20). ${ }^{3}$ Podemos notar que tanto o processo de tradução "inacabada" de que fala Simon, quanto as interrogações derridianas sobre a tradução do texto plurilíngue, remetem, igualmente, aos complexos mecanismos que atravessam as línguas enquanto códigos marcados internamente pela reflexibilidade da linguagem humana (Cf. RICOEUR, 2004, p. 25, grifo nosso).

\section{A noção de double bind}

A noção de double bind usada por Derrida para expressar uma "decisão impossível" de ser tomada pelo indivíduo diante de duas mensagens conflitantes entre si tem sua origem na Psicanálise. ${ }^{4}$ De acordo com Evando

\footnotetext{
3 A propósito de uma passagem do célebre Finnegans Wake, de James Joyce, Derrida comenta o seguinte: “'And he war' [...]. O he war não ata apenas, nesse lugar, um número incalculável de fios fônicos e semânticos no contexto imediato e em todo esse livro babélico; ele diz a declaração de guerra (em inglês) daquele que diz: "Eu sou aquele que sou" e que assim foi (war), terá sido intraduzível na sua performance mesma, ao menos nesse fato que se enuncia em mais de uma língua ao mesmo tempo, ao menos no inglês e no alemão. Se mesmo a tradução infinita de si esgotasse o fundo semântico, ela traduziria ainda uma lingua e perderia a multiplicidade do he war̆" (DERRIDA, 2002, p. 19-20, grifo do autor).

4 “A expressão double bind foi criada por Gregory Bateson em 1956, para designar o dilema (impasse duplo, coerção dupla ou duplo vínculo) em que fica encerrado o sujeito afetado pela esquizofrenia, quando não consegue dar uma resposta coerente a duas ordens de mensagens contraditórias e emitidas simultaneamente, quer por dois membros de sua família, quer pela família, de um lado, e a
} 
DOUBLE BIND E ESCRITA: a poética da tradução em textos da literatura do Quebec.

Renato Venancio Henriques de Sousa

Nascimento, o pensador francês "esvazia a expressão de seu conteúdo psicológico, enfatizando apenas seu valor 'dilemático', no ponto em que ela impõe uma decisão impossível entre duas solicitações que aparentemente se excluem” (NASCIMENTO, 1999, p. 98). Entendendo que cada língua é atravessada por uma pluralidade de línguas que nela inscrevem sua diferença, Derrida consegue pensar a questão da tradução para além da dicotomia entre dois idiomas e da ideia de pureza linguística. No contexto da desconstrução, "a tradução é um acontecimento que deflagra a língua, está entre as línguas e faz parte das línguas. O tradutor é aquele que vai transformar e produzir significados, produzir outras impurezas na língua para a qual traduz" (OTTONI, 2005, p. 51, grifo do autor).

Evando Nascimento propõe algumas traduções provisórias para o conceito, ele próprio um empréstimo do inglês, que Derrida "enxerta" no francês. São elas: “duplo elo, dupla ligação, dupla obrigação, dois gumes, duplo bando, dupla ereção, dupla banda, dupla borda ou beira" (NASCIMENTO, 1999, p. 98). ${ }^{5}$ Estas traduções realizam o que o próprio conceito anuncia: desvinculado de seu lastro psicanalítico, ele convoca e liga (o verbo to bind significa unir, ligar, atar) os diversos sentidos embutidos nas palavras, sentidos esses que são potencializados pelas combinações semânticas nascidas de aproximações e associações motivadas, no interior de um mesmo sistema linguístico, ou na confluência de várias línguas. A partir das traduções propostas pelo próprio Derrida, a saber, "double contrainte, double bande, double lien, double tranchant” (NASCIMENTO, 1999, p. 98), Nascimento

sociedade, de outro. A coerção vinda de fora acarreta desse modo uma resposta psicótica por parte do sujeito, porquanto ele não sabe decifrar a mensagem que lhe é dirigida" (ROUDINESCO \& PLON, 1998, p. 162).

5 Junia Barreto, tradutora de Torres de Babel, opta pelo termo híbrido "duplo bind" (DERRIDA, 2002: 41), que é explicado em nota de pé de página. Como se pode perceber, o double bind na tradução aparece como uma "liga" que instaura pactos semânticos das mais variadas procedências, ao sabor da criatividade e da sensibilidade infinita dos tradutores. 
DOUBLE BIND E ESCRITA: a poética da tradução em textos da literatura do Quebec.

Renato Venancio Henriques de Sousa

vai realizar o transbordamento de uma língua na outra, graças ao jogo de semelhanças e diferenças que se estabelece entre as palavras. Daí a ocorrência, por exemplo, de "gume", motivado por "tranchant" e de "ereção", por "bande": estes deslizamentos de sentido tornam-se possíveis somente a partir das traduções francesas.

Em "Tradução recíproca e double bind: transbordamento e multiplicidade de línguas", Paulo Ottoni nota que as traduções que suportam o double bind fazem surgir a mistura de línguas que o texto original, mesmo escrito num único idioma, carrega. "Nessas traduções", escreve ele, "há um jogo de implante e de enxerto entre as línguas que evidencia o fato de que há línguas, há uma permissão para que as línguas se misturem como já estão misturadas num único sistema linguístico" (OTTONI, 2005, p. 63). Partindo da análise de excertos de textos que encenam a multiplicidade dos códigos linguísticos, como Finnegans Wake, de James Joyce, o ensaio intitulado Glas, de Jacques Derrida, e Grande sertão: veredas, de Guimarães Rosa, Ottoni os confronta com as traduções, respectivamente, portuguesa, inglesa e alemã. Nelas, ressalta-se o movimento da tradução recíproca, que permite ao tradutor interferir no original a partir do paradoxo do double bind, que oscilando entre o traduzível e o intraduzível, permite fazer refluir as fronteiras imaginárias entre as línguas.

\section{A escrita migrante do Quebec}

No livro Ces étrangers du dedans: une histoire de l'écriture migrante au Québec (1937-1997), de Clément Moisan et Renate Hildebrand, que retraça sessenta anos da presença estrangeira na literatura quebequense, lemos que o termo "escrita migrante" ou "mestiça", criado pelo neo-quebequense Robert 
DOUBLE BIND E ESCRITA: a poética da tradução em textos da literatura do Quebec.

Renato Venancio Henriques de Sousa

Berrouët-Oriol em 1986, passa a substituir a expressão "escrita imigrante", usada até então para caracterizar a produção dos escritores imigrantes radicados na província francófona de Quebec e que utilizam o francês em suas obras. Tal substituição tinha como objetivo

designar precisamente uma maneira de escrever que deixa para trás os caminhos batidos, que vai ao sabor do acaso, que leva em conta os riscos da migração para outros países, outros céus, outros seres humanos, mas sobretudo para outras formas que denunciam as ideias feitas, os lugares comuns, os clichês (MOISAN \& HILDEBRAND, 2001, p. 264).

A mudança na maneira de nomear os escritos dos autores étnicos indica uma nova percepção do lugar destes últimos no interior do sistema literário do Quebec. Não mais percebida apenas do ponto de vista sociocultural, como deixava crer a designação "imigrante", a escrita migrante vai insistir muito mais no movimento, na deriva e nos diversos cruzamentos suscitados pela experiência do exílio, daí ser marcada pelo corpo e pela memória no esforço de reinvenção do país abandonado ou perdido.

Nos anos oitenta, o interesse crescente dos críticos e estudiosos da literatura do Quebec pelo fenômeno da escrita migrante concretiza-se na organização de eventos como o colóquio "Écrire la différence", realizado em Montreal, em 1985', na publicação de artigos em revistas literárias, entre outras iniciativas, que tentam dar conta das implicações dessa produção marcada pelo olhar imigrante. Considerando que o Canadá é um país tradicionalmente aberto à imigração, seria inevitável que a presença maciça de

\footnotetext{
${ }^{6}$ Reproduzimos a seguir um trecho da comunicação de Régine Robin, citado por Clément Moisan e Renate Hildebrand, no qual a autora de La Québécoite, ao falar sobre a escrita dos autores imigrantes, diz que "todo o problema [...] consiste em fazer encontrarem-se na escrita a palavra imigrante e a palavra migrante. Na minha opinião, o verdadeiro trabalho do escritor, a menos que ele se torne o cantor, o porta-voz das comunidades, é um perpétuo deslocamento dos estereótipos, um contínuo questionamento dos clichês, ele faz as imagens migrarem. E, de algum modo, não há nenhuma diferença entre o escritor étnico e os demais escritores" (MOISAN \& HILDEBRAND, 2001, p. 164, grifo nosso).
} 
DOUBLE BIND E ESCRITA: a poética da tradução em textos da literatura do Quebec.

Renato Venancio Henriques de Sousa

cidadãos vindos das mais variadas latitudes acabasse por inscrever-se no espaço literário, em seguida à conquista do espaço geográfico do país. Cabe ressaltar, no entanto, que a partir dos anos oitenta houve uma mudança nas cartografias da migração: antes marcadas pela imigração de origem europeia, elas passam a acolher cada vez mais indivíduos vindos de países do Terceiro Mundo.

\title{
As línguas de Sergio Kokis
}

Antoine Berman, no ensaio A prova do estrangeiro, escreve sobre a ambiguidade da posição do tradutor, habitado pela dialética da fidelidade e da traição, o que o leva a querer "forçar dos dois lados: forçar a sua língua a se lastrear de estranheza, forçar a outra língua a se de-portar em sua língua materna”. (BERMAN, 2002, p. 19) Em seguida, ele compara tal posição

\begin{abstract}
à dos escritores não franceses que escrevem em francês. Trata-se das literaturas de países francófonos, em primeiro lugar, mas também de obras escritas em nossa língua por escritores que não pertencem de forma alguma a zonas francófonas, como Beckett. Nós agruparemos essas produções sob a categoria do "francês estrangeiro". Elas foram escritas em francês por "estrangeiros" e carregam a marca dessa estranheza em sua língua e em sua temática. [...] Esse francês estrangeiro mantém uma relação estreita com o francês da tradução. [...] Em um bom número de casos, essas obras pertencem a espaços bi- ou plurilíngues, nos quais nossa língua vive uma situação particular: língua minoritária dominada, ou dominante, e, em todos os casos, confrontada a outras línguas, com relações frequentemente antagonistas (BERMAN, 2002, p. 19).
\end{abstract}

A escrita de Sergio Kokis, autor e pintor nascido no Rio de Janeiro tendo emigrado nos anos setenta para o Quebec, opera no registro da tradução com tanta frequência que seria penoso e excessivo elencar todas as passagens em que o romancista "traduz" um vocábulo ou uma expressão para o francês ou quando introduz algum elemento da cultura brasileira. Por outro lado, há 
DOUBLE BIND E ESCRITA: a poética da tradução em textos da literatura do Quebec.

Renato Venancio Henriques de Sousa

momentos em que ele simplesmente transcreve tal termo ou referência cultural sem se dar ao trabalho de explicá-lo ao leitor, por meio de nota ou outro procedimento tradutório (glosa ou explicitação, por exemplo). Outro aspecto que cabe ressaltar é a alusão constante à temática tradutória, presente em Errances (1996), romance de que tratamos neste artigo.

No terceiro romance do "ciclo brasileiro", que compreende Le pavillon des miroirs (1994) e Negão et Doralice (1995), Kokis aprofunda certos temas de sua predileção: a fascinação pelas línguas e pelas culturas estrangeiras, a centralidade da imaginação no processo criativo, a capacidade inventiva dos artistas e criadores em geral, o papel da fabulação entre os escritores. A essa temática, ele associa o elogio da deambulação espaço-temporal real ou imaginária referido pelo título e encarnado na trajetória de Boris Nikto, o personagem principal. Este, como o narrador de Le pavillon des miroirs, tem origem estrangeira pelo lado paterno. Tenente do Exército, estudante de matemática e militante comunista, Boris é obrigado a fugir do país por ocasião do golpe militar de 1964. Depois de um longo périplo pelo interior do Brasil, durante o qual intervêm uma série de peripécias, ele atravessa a Bolívia, alcança o Peru e embarca daí para a Europa. Levando uma existência clandestina, Boris percorre diversos países do continente, antes de estabelecerse na antiga República Democrática Alemã, onde se torna um poeta de renome.

Informado sobre a anistia concedida aos exilados políticos, ele retorna ao Brasil vinte anos depois, a exemplo de tantos outros expatriados. Esta viagem será decisiva para sua percepção profunda de si mesmo como estrangeiro. Este retorno, cheio de decepções, encontros e revelações, sela o abandono definitivo de toda ideia de origem, simbolizado no adeus ao pai morto, cuja sepultura ele tem a ocasião de visitar, na Baixada Fluminense. A errância sem 
DOUBLE BIND E ESCRITA: a poética da tradução em textos da literatura do Quebec.

Renato Venancio Henriques de Sousa

fim de Boris, globe trotter insaciável, que exerceu diversos biscates antes de trabalhar no Instituto de estatísticas sociais de Rostock, onde vive com Olga, se exprime também no domínio das línguas estrangeiras. Poeta de língua alemã, tradutor bissexto, transitando com facilidade por algumas das grandes línguas de civilização europeia, ele chega a lamentar "son portugais appauvri, devenu plus celui de l'Angola ou du Mozambique que celui du Brésil [.] Cette impression de perte de sa langue maternelle lui semblait parfois une trahison" (KOKIS, 1996, p. 30). Suspeitando que "les critiques officiels n'étaient pas trop agressifs à son égard puisqu'il était étranger" (KOKIS, 1996, p. 33), Boris acaba se perguntando se sua identidade de escritor não seria mais um disfarce, considerando que, em sua poesia estrangeira, "la langue des autres devenait mensonge et tricherie" (KOKIS, 1996, p. 30).

Vamos dar dois exemplos nos quais o double bind, a tradução recíproca, se faz presente. Durante o período em que se hospeda num hotel barato da Lapa, Boris Nikto recebe a visita de uma prostituta de cerca de dez anos, enviada pelo proprietário, velho conhecido do protagonista. Depois de trocarem algumas palavras, Boris, indagado pela menina se a achara bela, responde-lhe: "Oui, Linda, je te trouve comme ton nom, très jolie" (KOKIS, 1996, p. 304, grifo nosso). Encontramos aqui um procedimento de explicitação que esclarece o leitor francófono acerca do sentido do nome próprio que, de outro modo, não seria compreendido. Kokis procede a uma “transferência de sentido", como sugere Michel Ballard (1998, p. 219), indo na contramão da tendência a se tomar o nome próprio como uma unidade linguística destituída de sentido. Ao fim do encontro em que os personagens apenas conversam, a menina, antes de sair, oferece os serviços de seu irmão mais novo. Diante da surpresa de Boris em saber que Linda tinha um irmão caçula, aquela lhe informa: “- Oui, il est petit et très propre. Il s'appelle 
DOUBLE BIND E ESCRITA: a poética da tradução em textos da literatura do Quebec.

Renato Venancio Henriques de Sousa

Cassula" (KOKIS, 1996, p. 306, grifo nosso). Embora possamos estranhar que o nome comum "caçula" seja utilizado como antropônimo (atente-se ainda para a mudança da grafia) e que talvez fosse melhor considerá-lo, neste contexto, como um apelido carinhoso, nós, leitores de língua portuguesa, encontramos no nome do irmão menor de Linda um eco da pergunta de Boris: "- Tu as un petit frère?” Pouco importa se, para o leitor francófono, "Cassula" mantenha seu coeficiente de intraduzibilidade, o fato é que o leitor brasileiro de francês suporta, aqui, o double bind, a tradução recíproca, do francês para o português ("petit frère" $\rightarrow$ "irmão menor" $\rightarrow$ "Cassula" $\rightarrow$ "caçula"), a partir do vínculo estabelecido pela escrita tradutória de Kokis no interior do francês ("petit frère $\rightarrow$ "Cassula").

Longe de pretendermos esgotar um tema recorrente na narrativa deste romance, vamos mencionar algumas passagens nas quais se evidencia $o$ leitmotif da "poética da tradução" kokisiana. No capítulo 20, encontramos uma passagem em que o autor faz uso da tradução literal de vocábulos do português, criando palavras assignificantes em francês. No episódio de que trataremos a seguir, Kokis deixa a um personagem a missão de explicar o sentido de uma palavra utilizada num sentido novo, que o protagonista desconhece.

O capítulo relata a peregrinação de Boris pela Baixada para visitar o túmulo do pai, que fora enterrado num cemitério situado em Imbariê, distrito de Duque de Caxias. Na companhia de Pindoca, motorista de táxi, personagem que aparece também em Negão et Doralice, Boris segue as indicações do mapa feito por uma amiga. Antes de se dirigirem ao cemitério, eles passam pela Taquara, onde vive Julieta, a companheira do pai até seus momentos finais. Durante o trajeto, Pindoca faz as vezes de guia turístico, diante de um Boris cada vez mais atarantado com o espetáculo de degradação 
DOUBLE BIND E ESCRITA: a poética da tradução em textos da literatura do Quebec.

Renato Venancio Henriques de Sousa

e miséria em que se transformou sua cidade natal. Depois de deixarem a Avenida Brasil e tomarem a direção de Duque de Caxias, eles divisam uma favela construída nas cercanias de um cemitério.

O motorista informa ao carona que se trata de uma localidade extremamente perigosa principalmente à noite, quando os motoristas são obrigados a pagar pedágio a policiais corruptos, além de funcionar como um centro da prostituição de travestis. Não admira que os urubus se fartem, a cada manhã, da carne fresca dos cadáveres, ou "les jambons, comme les gens les appellent” (KOKIS, 1996, p. 383, grifo do autor). Como Boris desconhece o termo "presunto" referido ao corpo de pessoas assassinadas, abandonado em locais ermos, Pindoca explica-lhe detalhadamente nos seguintes termos:

- [...] L'appelation est ancienne, pour dire la viande froide. Sauf qu'autrefois il y en avait moins, les gens n'en parlaient pas avec autant de familiarité. Comme Rio de Janeiro détient maintenant le record mondial des assassinats, on préfère dire jambons, plutôt que cadavres (KOKIS, 1996, p. 383, grifo nosso).

Note-se que, neste caso, a explicitação do termo desconhecido torna dispensável o uso da nota explicativa, como ocorre em outras passagens. Além disso, tal recurso confere mais verossimilhança ao episódio, uma vez que mostra que Boris, ausente do país há duas décadas, não conhece o sentido figurado de "presunto" atribuído a cadáver, de uso mais recente na língua portuguesa do Brasil.

Mais adiante, a descrição de Imbariê é a ocasião para Kokis mostrar sua veia cômica na designação burlesca de religiões e seitas evangélicas de extração nacional:

Embarié avait l'allure d'un village détruit par une catastrophe. Les bâtiments abîmés par le temps étaient entourés de baraques en boue séchée aux toits de chaume. [...] Une vieille église solitaire en stuc craquelé contrastait avec plusieurs longues cabanes en forme de hangar, décorées de drapeaux et d'inscriptions, qui abritaient les cultes reformés 
DOUBLE BIND E ESCRITA: a poética da tradução em textos da literatura do Quebec.

Renato Venancio Henriques de Sousa

aux noms bizarres: Baptistes de la Rédemption, Pentecôtistes de la fin du monde et, plus prosaïquement, Les fans de la Bible, La vraie parole vraie et Les gardiens de but du Christ (KOKIS, 1996, p. 391, grifo do autor). ${ }^{7}$

Ressalte-se a referência aos "fãs" com o sentido de seguidores da Bíblia, alusão plausível às seitas envangélicas com seus cultos transmitidos pela televisão, de grande apelo popular, assim como aos shows de música gospel, que atraem multidões. Já "Os goleiros de Cristo" remetem ao universo do esporte mais popular do "país do futebol", visão de uma apropriação do sagrado pelo profano, praticada pelas novas religiões, que visam atingir as massas de excluídos, privados de toda esperança na vida terrena e na justiça dos homens.

No capítulo 21, Boris Nikto encontra um ex-professor da faculdade de Matemática com quem conversa longamente. Num dado momento, o professor Mansour diz o seguinte: "En moins de deux, le souvenir du théorème de Gödel a repris le dessus et je n'ai plus jamais répété de fallacies historicistes" (KOKIS, 1996, p. 427, grifo nosso). Uma consulta ao dicionário Le Petit Robert nos informa que a palavra fallacie não existe em francês, embora o adjetivo fallacieux e o advérbio fallaciensement estejam dicionarizados. Poderíamos pensar numa interferência do português falácia, que pode ter passado despercebida no momento da revisão. Ou então, pode ser que Kokis tenha querido "forçar" a hospitalidade do francês a receber um tal "neologismo", além de marcar, desta forma o caráter estrangeiro do texto. De todo modo, o vocábulo fallacie existiria como virtualidade do léxico da língua francesa, uma vez que tanto fallacieux quanto fallacieusement são de uso corrente,

\footnotetext{
7 A propósito da grafia "Embarié", note-se a troca do I pelo E, além da mudança do acento na sílaba tônica (de circunflexo para agudo), esta última visando talvez manter, em francês, a pronúncia do nome do vilarejo mais próxima do português.
} 
DOUBLE BIND E ESCRITA: a poética da tradução em textos da literatura do Quebec.

Renato Venancio Henriques de Sousa

bastando que se criasse um termo derivado, procedimento comum para a formação de novas palavras nas línguas naturais. ${ }^{8}$

Encontramos em Errances, além das diversas alusões ao universo da tradução, a começar pelo fato de o protagonista ser um tradutor bissexto, tendo inclusive sido convidado a exercer esta atividade no momento de seu retorno ao Brasil, um episódio especialmente relevante no que diz respeito ao motivo da tradução. Referimo-nos ao capítulo 13, que relata a estada de Boris em Bolonha, na Itália, na casa de dois amigos livreiros, Gaetano e Gina Vescovo. Como em outros momentos deste romance marcado por longos diálogos, que são a ocasião para o autor derramar sua extensa cultura sobre os mais variados assuntos, o interregno italiano apresenta algumas conversas sobre arte e cultura, nas quais se faz referência aos projetos de edição de obras traduzidas dos irmãos Vescovo, que possuem uma pequena editora especializada na reedição de livros voltados para um público seleto. Poderíamos enumerar as seguintes informações:

1) traduções em curso:

- "extraits de Lautréamont” pelo professor Vanucci (KOKIS, 1996, p. 258);

- os simbolistas russos Akhmatova, Blok, Mandelstam e Essenine (Iessenin, em português) por Jacobbi, amigo de Gaetano (KOKIS, 1996, p. 259);

2) referência a uma ode de Ezra Pound, intitulada "Usure", traduzida por Gina: "Je l'ai moi-même traduite, à nouveau, rien que pour moi et Gaetano. Ce poème nous fortifie tout en nous rappelant l'exil, la vraie patrie des poètes" (KOKIS, 1996, p. 261-262, grifo nosso);

\footnotetext{
${ }^{8}$ Cf. a interpretação derridiana de uma passagem d'“A tarefa do Tradutor", de Benjamin: "Dir-se-ia [...] que cada língua está como que atrofiada na sua solidão, magra, parada no seu crescimento, enferma. Graças à tradução, dito de outra forma, a essa suplementaridade linguística pela qual uma língua dá a outra o que lhe falta, e lho dá harmoniosamente, esse cruzamento das línguas assegura o crescimento das línguas, e mesmo esse 'santo crescimento das línguas' 'até o termo messiânico da história'. [...]” (DERRIDA, 2002, p. 67-68).
} 
DOUBLE BIND E ESCRITA: a poética da tradução em textos da literatura do Quebec.

Renato Venancio Henriques de Sousa

3) menção de Gaetano a "une jolie traduction des Carmina burana dans une langue merveilleusement naïve et populaire. Ils l'ont sorti dans la pochette d'un microsillon de Carl Orff' (KOKIS, 1996, p. 263);

4) sugestão de tradução:

- poemas de Louise Labé, de Rutebeuf, Villon e Ronsard "que le professeur Vanucci se ferait un plaisir de [...] traduire" (KOKIS, 1996, p. 263. Cf. p. 258, primeira referência a Louise Labé).

Como podemos notar, a tradução - aqui relacionada a questões envolvendo a edição de livros raros, tendo como pano de fundo um interessante debate em torno da língua italiana e da poesia enquanto gênero aparece como um motivo estruturante neste livro, que se apresenta como um diálogo e uma viagem incessante entre línguas e culturas.

Concluindo esta parte, poderíamos afirmar que a escrita kokisiana põe em cena personagens que, pela vivência liminar, no caso de Negão, e intercultural, no caso do narrador de Le pavillon des miroirs e de Boris Nikto, aparecem como metáforas vivas da tradução como prática visando lançar pontes entre as lacunas encontradas nas línguas e culturas. Neste sentido, o efeito de estranhamento causado pela leitura de um texto escrito em francês por um autor de origem brasileira, que ainda por cima evoca a realidade de nosso país, revela a estranheza que nos habita e, por que não, o caráter "estrangeiro" de nossa própria cultura, traduzida e transtornada (no sentido de desfigurada) pelo prisma deformante das lentes de Kokis. Em contrapartida, não deixa de ser curioso pensarmos no mesmo efeito, desta vez percebido de outro ponto de vista, isto é, através da leitura feita por um leitor francófono, como o "reflexo" de uma escrita outra, estrangeira e estranha. 
DOUBLE BIND E ESCRITA: a poética da tradução em textos da literatura do Quebec.

Renato Venancio Henriques de Sousa

\section{O conto "Oui or No" de Monique Proulx}

Os problemas relativos à língua e à identidade no Quebec refletem toda a ambiguidade da história de um dos povos fundadores do Canadá. Ainda que não constitua uma nação autônoma, esta província comporta-se, em muitos casos, como tal, o que tem provocado tensões com o governo federal, cada vez que os partidários da autodeterminação quebequense acenam com um plebiscito visando à independência. No último plebiscito, realizado em 1995, os defensores do "sim" à soberania perderam por uma pequena margem de votos, o que levou o primeiro ministro do Quebec da época, Jacques Parizeau, a pôr a culpa "no dinheiro e no voto étnico". Esta declaração infeliz, motivada pela amargura da derrota, varreu por um bom tempo as veleidades de autonomia da província francófona, já que pôs o dedo na ferida da sociedade quebequense que convive cada vez mais com as "minorias visíveis" representadas pelos imigrantes, também conhecidos como "neoquebequenses". Estes últimos, ora imigrantes, ora exilados, vivem em sua maioria em Montreal, metrópole aberta a todos os pertencimentos identitários, "cidade sonhada do trans" (HAREL; GRAVILI, 2000, p. 146).

Com efeito, Montreal, como uma pequena Nova York, abriga comunidades das mais diversas origens: chinesa, "latina" (entenda-se latinoamericana), italiana, judaica, haitiana, portuguesa... Não se pode esquecer de que se trata de uma cidade onde convivem duas comunidades linguísticas, uma francófona, majoritária, e outra anglófona. No entanto, se as fronteiras linguísticas podem sobrepor-se, as barreiras de comunicação não são menos reais conforme se tenha o inglês ou o francês como única língua.

\footnotetext{
9 Palavras do primeiro ministro em seu discurso feito depois da divulgação do resultado do plebiscito, conforme reportagem de La boîte noire, programa da televisão quebequense, exibido na TV 5 Monde, em 06 de abril de 2005. No ensaio de Moisan e Hildebrand, lemos, numa nota de pé de página, que Jacques Parizeau era casado com uma neo-quebequense, a escritora de origem polonesa Alice Parizeau (Cf. MOISAN \& HILDEBRAND, 2001, p. 307).
} 
DOUBLE BIND E ESCRITA: a poética da tradução em textos da literatura do Quebec.

Renato Venancio Henriques de Sousa

A coletânea de contos Les aurores montréales (2005), da escritora e roteirista Monique Proulx, compõe-se de textos que celebram o mosaico de culturas que convivem, nem sempre de maneira harmoniosa, em Montreal. Segundo Bernadette Porto,

\begin{abstract}
enquanto lugar de produção de sentidos, em que se deslocam diferentes atores sociais e representantes de culturas diversas, e em que coexistem e se esbarram diferenças múltiplas (econômicas, identitárias, memoriais e ideológicas), Montreal aparece na obra Les aurores montréales de Monique Proulx como um texto polifônico por excelência. Dando voz e espaço a seres deslocados, exilados e desabrigados - marginais e marginalizados, em suma - a autora se mostra sensível à questão da alteridade. $\mathrm{Na}$ multiplicidade de pontos de vista presentes nas novelas de Proulx, depreende-se sobretudo a perspectiva de seres paratópicos, isolados em sua solidão e abandono e que tentam, às vezes, ocupar o lugar do outro numa espécie de jogo identitário (PORTO, in FIGUEIREDO \& PORTO, 2007, p. 147).
\end{abstract}

Mais adiante, ela acrescenta: "cidade inacabada, nova Babel, marcada por tensões sociais, econômicas, linguísticas e políticas, Montreal define-se no universo de Proulx enquanto construção em aberto e em trânsito, como a própria escrita” (PORTO, in FIGUEIREDO \& PORTO, 2007, p. 147).

O conto que pretendemos analisar, intitulado "Oui or No", trata de separação, traição e tradução. Nele, o destino de um casal de jornalistas quebequenses se mistura com o destino da província do Quebec, no momento do plebiscito de 1995. Como no primeiro plebiscito, em 1980, a população deverá se manifestar com relação à separação da província francófona do resto do Canadá ou sua permanência na confederação canadense, bastando para isso responder com o "sim" ou com o "não", a que o título do conto alude. Quinze anos depois, o peso do chamado "voto étnico" será decisivo para a vitória do "não", o que será percebido como uma 
DOUBLE BIND E ESCRITA: a poética da tradução em textos da literatura do Quebec.

Renato Venancio Henriques de Sousa

traição dos neo-quebequenses pelos quebequenses de origem (de souche, ou pure laine). ${ }^{10}$

Jocelyn Létourneau, no artigo "A questão regional no Canadá e a autodeterminação quebequense", analisa os conflitos e tensões entre províncias no interior da confederação canadense e, em especial, o projeto quebequense de autonomia político-administrativa que, em tempos de globalização, se afirma muito mais como um movimento econômico. Falando do nacionalismo quebequense, o autor acrescenta que

\begin{abstract}
aos olhos de numerosos comentaristas políticos, a eleição do Partido Quebequense em setembro de 1994 coincidiu com a reativação, entre os franco-quebequenses, de um sentimento latente de autonomia que deveria, mais cedo ou mais tarde, ser consumado. O resultado apertado do plebiscito de outubro de 1995 representa, segundo esses comentaristas, uma prova adicional da marcha inexorável, "natural" chegaram a dizer com exagero - dos quebequenses em direção à autonomia política. [...] (LÉTOURNEAU, in BÉLANGER, HANCIAU $\&$ DION, 1999, p. 270).
\end{abstract}

No plebiscito de 1995, evocado no texto de Proulx, a margem de diferença entre os defensores da autonomia e os partidários da permanência foi bastante pequena. Basta dizer que “59,6\% da população do Quebec aprovou o projeto de autonomia com parceria, enquanto que $60,4 \%$ se opôs a ele" (LÉTOURNEAU, in BÉLANGER, HANCIAU \& DION, 1999, p. 270).

\footnotetext{
${ }^{10}$ Lemos, na citação a seguir, como o casal de jornalistas reage diante da rejeição da autonomia do Quebec por parte dos neo-quebequenses: “[...] Il y a des moments devant le téléviseur où Filippo et Éliane ne parlent pas. Lorsqu'ils entendent les témoignages des gens venus d'ailleurs, installés ici depuis longtemps, et qui nient toujours l'existence du petit pays dans lequel ils nichent confortablement, Filippo et Éliane sont étreints par une douleur qui leur écrase les mots dans la bouche. Les mots n'existent pas pour condamner ces gens venus d'ailleurs, aux bonnes têtes sympathiques, qui rejettent, de leurs hôtes, le droit à la survie. [...]” (PROUXL, 2005, p. 176).
} 
DOUBLE BIND E ESCRITA: a poética da tradução em textos da literatura do Quebec.

Renato Venancio Henriques de Sousa

No conto, vemos como a "nação" quebequense se debate num leito estreito demais para comportar suas contradições, seu caldo de cultura cada vez mais híbrido. No contexto do casal de jornalistas Éliane e Philippe, a alternativa referida no título remete à escolha da mulher que trai o marido com um canadense de língua inglesa, Nick Rosenfeld. Ela vai optar pelo "não", isto é, por não deixar o marido ao invés de cruzar a fronteira linguística e cultural para viver em Toronto com o amante. O "sim" é, aqui, índice de permanência de uma vida de casal que se dá no conforto do unilinguismo identitário. Já no âmbito da província do Quebec, há períodos de tensão entre as comunidades franco, anglo e alófona, sem falar nos momentos de crise nas relações com Ottawa. De todo jeito, tanto na vida dos casais quanto na dos países, o divórcio é um horizonte possível, ainda que nem sempre realizado.

No texto de Proulx, o amante anglo-canadense conota a paixão sexual. A língua inglesa aparece como a expressão audível dessa sedução e dessa paixão, que se traduz por uma intensa emoção. Na cama do amante de Toronto, a musicalidade dessa língua corporifica o encantamento das palavras sussurradas ao telefone: "Oh Éliane. My dear. Oh you. You" (PROULX, 2005, p. 170, grifo da autora). Ainda que Nick afirme entender o francês, as conversas entre Éliane e o amante se dão em inglês:

[...] La conversation est périlleuse, bien sûr puisqu'elle doit naviguer entre l'écueil de l'émotion et l'écueil des mots étrangers. Chaque fois qu'à l'autre bout du fil Nick raccroche, elle cherche et trouve trop tard dans le 
DOUBLE BIND E ESCRITA: a poética da tradução em textos da literatura do Quebec.

Renato Venancio Henriques de Sousa

dictionnaire ce qu'il aurait fallu lui dire, elle prépare des phrases terriblement efficaces qui s'évanouissent au moment de les prononcer. (Your accent is adorable.) La conversation est périlleuse et inégale. Quand enfin elle parvient, après de laborieux entortillements, à lui exprimer le bouleversement que lui cause sa voix au téléphone et la frayeur surtout que lui cause ce bouleversement, sa réponse à lui la foudroie. (Same here.) Oh cette langue lapidaire qu'il a, cette langue en coups de poing. Comment résister à une langue qui va droit au but et qui persiste si longtemps dans la mémoire? (Ob Éliane. My dear. Ob you. You) (PROULX, 2005, p. 172-173, grifo da autora).

A insegurança linguística da jornalista remete à perda do controle típico das relações marcadas pela paixão, pela dominação, e ao abandono de sua zona de conforto. A passagem para outra língua e cultura aparece, neste contexto, como uma experiência desestabilizadora. Além disso, ao se dar conta da alteridade do amante, ela se percebe igualmente como uma estrangeira aos olhos dele: 'Il prononce son nom 'Alien', comme le monstre de l'espace, comme l'étranger qu'ils sont l'un pour l'autre" (PROUXL, 2005, p. 172, grifo nosso). Com Alien-Éliane, o texto de Proulx suporta a tradução recíproca criada por um efeito de oralidade, uma vez que a pronúncia da palavra inglesa alien, $i$. e. estrangeiro, remete ao nome da jornalista da mesma forma que o antropônimo Éliane pronunciado por um anglófono assemelhase à primeira.

Com o tempo, Éliane observa que o comportamento de Nick se altera conforme ele se encontre em pé ou deitado: "Debout, il devient raide et prisonnier de phrases compassées (We get along so well. I am sure we will be friends.) 
DOUBLE BIND E ESCRITA: a poética da tradução em textos da literatura do Quebec.

Renato Venancio Henriques de Sousa

Allongé, il brûle comme un volcan aux laves inépuisables. (Ob Éliane. Ob lovely. Oh you. You.)" (PROULX, 2005, p. 174-175, grifo da autora). Sentindo-se rejeitada, uma vez que o amante parou de ligar para ela, a jornalista decide escrever-lhe, mas percebe a dificuldade em lidar com as palavras do inglês:

[...] Ce n'est pas facile à dominer. Il faut se battre encore une fois sur son terrain à lui, palper sous tous leurs angles les mots étrangers pour en pressurer l'âme. Éliane traduit mentalement dans la langue de Nick Rosenfeld tout ce que'elle entend, en manière d'exercice. Pass me the butter. Give me a break. Do you agree with the law voted by the National Assembly and proclaming a new bed? Yes or No. Elle traduit les consultations télédiffusées en différé le soir (PROULX, 2005, p. 176, grifo da autora).

Notemos aqui que Éliane começa a traduzir mentalmente tudo o que se diz a sua volta e até os programas de televisão transmitidos em francês. Esse esforço em verter para o inglês os enunciados que ouve em sua língua materna corresponde a uma tentativa de dominar esse código lapidar que emana da boca de Nick Rosenfeld com sua "voix de sirène" (PROULX, 2005, p. 173) tal qual um filtro mágico. Essa boca "en possession du discours" tem ainda a capacidade de se transformar em "organe sexuel" (PROULX, 2005, p. 170) para melhor seduzir a amante quebequense.

Sentada no sofá ao lado do marido, que ela chama carinhosamente de Filippo, Éliane assiste a um programa no qual ele entrevista chefes de nações indígenas, que manifestam em inglês sua oposição à autonomia do Quebec. Ela se põe a traduzir as palavras do marido jornalista e percebe o perigo desse jogo: "Mais traduire mentalement Filippo est une expérience difficile, qui la 
DOUBLE BIND E ESCRITA: a poética da tradução em textos da literatura do Quebec.

Renato Venancio Henriques de Sousa

laisse terriblement honteuse. C'est à ce moment-là qu'elle sent qu'elle le trabit vraiment, que'elle le trabit beaucoup plus qu'avec Nick Rosenfeld” (PROULX, 2005, p. 177, grifo nosso). Não há como não pensarmos no famoso adágio "traduttore, traditore", associado, neste contexto, ao topos da traição e do triângulo amoroso criado por Monique Proulx.

$\mathrm{O}$ double bind aparece ainda mais explicitamente numa passagem que mostra como a paixão por Nick ameaça a felicidade do casal. Sentados no sofá, Éliane e Philippe-Filippo acompanham com grande interesse as notícias sobre o plebiscito. A efervescência desse momento histórico fez, inclusive, uma vítima: um homem morreu de infarto devido à emoção de participar de algo tão importante. Na sala, o casal conversa sobre o acontecimento. Philippe ignora o risco que seu casamento está correndo:

Pour la première fois Éliane est gênée par la chaleur du corps de Philippo. Pour la première fois, elle le sent en danger. Elle se serre contre lui pour le protéger de Nick Rosenfeld. Danger. Jeopardy. Elle a longtemps cru que Jeopardy était une sorte de léopard, avant de regarder dans le dictionnaire (PROULX, 2005, p. 172, grifo da autora).

Danger e Jeopardy, dispostos fraternalmente lado a lado, como o casal estendido no sofá, remetem à ideia de perigo, de risco iminente. No conto, a palavra danger (grafada de forma idêntica tanto em francês quanto em inglês, sendo ainda amplamente conhecida do público leitor), aparece identificada à sua tradução inglesa jeopardy. Éliane, no entanto, associa esta última à palavra léopard, com a qual apresenta uma certa semelhança no que diz respeito à 
DOUBLE BIND E ESCRITA: a poética da tradução em textos da literatura do Quebec.

Renato Venancio Henriques de Sousa

grafia. O leopardo, por sua vez, conota uma vasta gama de sentidos, desde os positivos, associados aos grandes felinos em geral, que simbolizam o poder, a elegância e a velocidade, até os negativos, pois são caçadores ferozes e podem atacar o homem. Além disso, representa a nação inglesa, em cujas armas figuram três leopardos. ${ }^{11}$

Portanto, o personagem de Nick Rosenfeld, canadense de língua inglesa, é identificado ao perigo, podendo causar a separação do casal, num paralelismo evidente com a história do pequeno país debatendo-se num casamento infeliz com o grande país, que ameaça submergi-lo em seus lençóis pantanosos (Cf. PROULX, 2005, p. 169).

Finalmente, Éliane faz uma descoberta que terá um efeito devastador sobre sua percepção do amante. Ao pronunciar o nome dele diante de pessoas de seu meio, ela fica sabendo que não somente Nick é bastante conhecido como também é conhecida sua fama de sedutor, tendo em seu ativo uma quantidade inimaginável de mulheres que levou para a cama... A jornalista não é senão uma presa a mais no extenso rol de conquistas desse verdadeiro "predador", desse leopardo cheio de charme. Ela então desiste de escreverlhe.

\footnotetext{
${ }^{11}$ De acordo com O dicionário de símbolos, "O leopardo é o símbolo da altivez; nessa qualificação, sem dúvida, constitui o emblema tradicional da Inglaterra. É também um animal caçador. [...] Simboliza a ferocidade, ao mesmo tempo que a habilidade e a força" (CHEVALIER \& GHEERBRANT, 1991, p. 544, grifo dos autores).
} 
DOUBLE BIND E ESCRITA: a poética da tradução em textos da literatura do Quebec.

Renato Venancio Henriques de Sousa

No final do conto, o casal de jornalistas participa ao vivo de um programa especial sobre a apuração dos votos do plebiscito quando sai o resultado final. Diante da vitória do "Não", ambos fazem comentários moderados juntamente com outros convidados, escolhendo bem as palavras para avaliar os acontecimentos. Mais tarde, sucumbindo à emoção, eles se abraçam no sofá da sala. Tomados pela decepção, Éliane e Philippe têm que lutar contra o ódio que sentem pela covardia dos "moutons courageux" (PROULX, 2005, p. 178), por essa "moitié des gens du pays [qui] a peur de vivre dans un lit inconnu" (PROULX, 2005, p. 178). Eles, por sua vez, pertencem à "l'autre moitié [qui] a peur de mourir dans un lit connu. Comment savoir laquelle de ces deux peurs est la plus digne?” (PROULX, 2005, p. 178).

No dia seguinte ao resultado do plebiscito, Nick telefona para Éliane. Paralisada pela desconfiança, ela não fala nada, enquanto "il dit ces quelques mots, les plus tendres qu'elle ait entendus dans sa langue, il ne répète que ces quelques mots d'apaisement véritable. (I'm sorry. I'm sorry.)" (PROULX, 2005, p. 178-179). Podemos ler as últimas palavras de Nick de duas maneiras, na medida em que remetem tanto ao fim da relação do casal quanto ao resultado do plebiscito sobre a independência do Quebec. 
DOUBLE BIND E ESCRITA: a poética da tradução em textos da literatura do Quebec.

Renato Venancio Henriques de Sousa

A possibilidade de escolha aludida no título do conto permeia uma série de situações nas quais a ambiguidade se faz presente, remetendo, e não poderia ser diferente, à prática tradutória. Além disso, como vimos com Derrida, o título está escrito em mais de uma língua ("Oui or No"), o que aponta para a noção de double bind, para a tradução recíproca no que ela tem de dilemático, conforme teorizado no ensaio Torres de Babel.

\section{Considerações finais}

Gostaríamos de concluir dizendo que as reflexões apresentadas neste artigo a partir de textos atravessados pela "poética da tradução", nos quais ocorre o double bind - o transbordamento de uma língua na outra -, abrem perspectivas para a percepção do texto literário como o lugar de uma migração constante de sentidos.

Dentro desta perspectiva, a escrita habitada pela presença do Outro estabelece novos contratos de leitura que convocam o diálogo entre várias identidades culturais, em consonância com as práticas artísticas da pósmodernidade, que dão cada vez mais espaço para a irrupção de discursos nascidos das tensões e contradições de sujeitos marcados pela alteridade.

\section{Referências bibliográficas}


DOUBLE BIND E ESCRITA: a poética da tradução em textos da literatura do Quebec.

Renato Venancio Henriques de Sousa

BALLARD, Michel. La traduction du nom propre comme négociation. Palimpsestes, 11, 199-223, 1998.

BERMAN, Antoine. A prova do estrangeiro: cultura e tradução na Alemanha romântica. Bauru, SP: EDUSC, 2002.

BRISSET, Annie. Sociocritique de la traduction: Théâtre et altérité au Québec (1968-1988). Québec: Le Préambule, 1990. (Coll. L’Univers du discours)

CHEVALIER, Jean \& GHEERBRANT, Alain. Dicionário de simbolos: mitos, sonhos, costumes, gestos, formas, figuras, cores, números. Rio de Janeiro: José Olympio, 1991.

DERRIDA, Jacques. Torres de Babel. Belo Horizonte: Editora da UFMG, 2002.

DICTIONNAIRE LE PETIT ROBERT DE LA LANGUE FRANÇAISE. Paris: Le Robert, 1984.

HAREL, Simon. Mémoires de l'identité, mémoires de l'oubli: formes subjectives de l'écriture migrante au Québec. In: GRAVILI, Anne de Vaucher (dir.). D'autres rêves: Les écritures migrantes au Québec. Veneza: Supernova, 2000, 143-161.

KOKIS, Sérgio. Le pavillon des miroirs. Montréal: XYZ, 1994.

. Negão et Doralice. Montréal: XYZ, 1995.

. Errances. Montréal: XYZ, 1996.

LÉTOURNEAU, JOCELYN. A questão regional no Canadá e a autodeterminação quebequense. In: BÉLANGER, Alain, HANCIAU, Nubia \& DION, Sylvie. $A$ América Francesa: introdução à cultura quebequense. Rio Grande: Fundação Universidade Federal do Rio Grande, 1999, 265-292.

MOISAN, Clément \& HILDEBRAND, Renate. Ces étrangers du dedans: une histoire de l'écriture migrante au Québec (1937-1997). Montréal: Nota Bene, 2001.

NASCIMENTO, Evando. Derrida e a Literatura: "notas" de literatura e filosofia nos textos da Desconstrução. Niterói: EdUFF, 1999. (Coleção Ensaios; 14)

OTTONI, Paulo. Tradução manifesta: double bind \& acontecimento, seguido de Fidelidade a Mais de Um: merecer herdar onde a genealogia falta, de Jacques Derrida. Campinas, SP: Editora da UNICAMP; São Paulo: EDUSP, 2005.

PORTO, Maria Bernadette Velloso. Andarilhos, vagabundos e mendigos: desvíos, devires e lugares da alteridade. In: FIGUEIREDO, Eurídice \& (orgs.). Figurações da alteridade. Niterói: EdUFF, 2007, 131-159.

PROULX, Monique. Les aurores montréales: nouvelles. Montréal: Boréal, 2005. 
DOUBLE BIND E ESCRITA: a poética da tradução em textos da literatura do Quebec.

Renato Venancio Henriques de Sousa

RICOEUR, Paul. Sur la traduction. Paris: Bayard, 2004.

ROUDINESCO, Elizabeth \& PLON, Michel (org.). Dicionário de Psicanálise. Rio de Janeiro: Jorge Zahar Ed., 1998.

SIMON, Sherry. Le trafic des langues: Traduction et culture dans la littérature québécoise. Montréal: Boréal, 1994. 